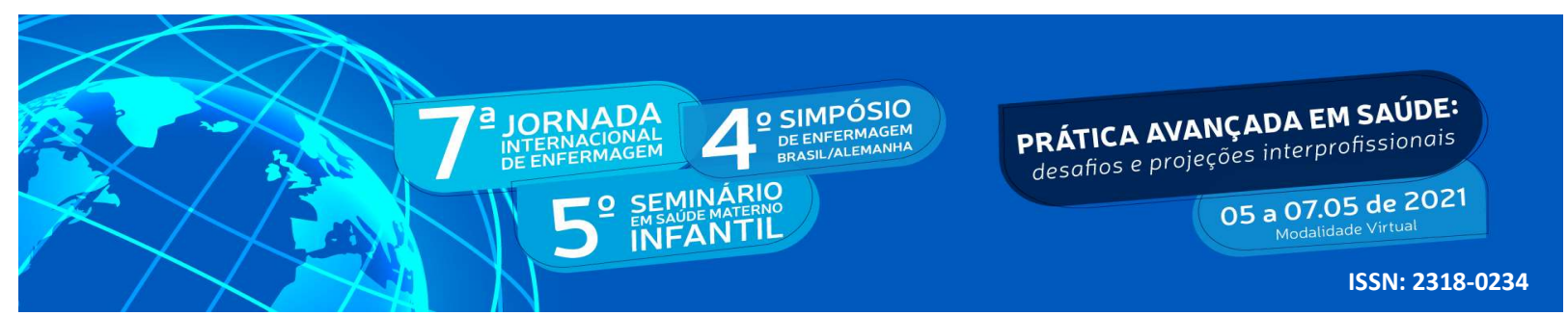

DOI: http://doi.org/10.48195/jie2021-073

\title{
ESTÁGIO SUPERVISIONADO EM ENFERMAGEM NA ATENÇ̃̃O BÁSICA NO CONTEXTO DA COVID-19: RELATO DE EXPERIÊNCIA
}

\section{Vinícius Alves de Souza ${ }^{1}$; Isabel Pires Barra ${ }^{2}$; Ana Karolina de Lima Alves da Silva ${ }^{3}$; Paulo Wendel Ferreira Fonseca ${ }^{4}$; Magnólia Carvalho Aquino Gonzaga ${ }^{5}$; Paula Fernanda Brandão Batista dos Santos ${ }^{6}$}

\begin{abstract}
RESUMO
Objetivo: relatar as experiências de estudantes de enfermagem durante o estágio curricular supervisionado na atenção primária, no cenário da pandemia de Coronavírus. Método: relato de experiência desenvolvido por estudantes do curso de graduação em Enfermagem durante o estágio curricular supervisionado em um serviço de atenção básica, no Estado do Rio Grande do Norte. O estágio foi desenvolvido em uma Estratégia Saúde da Família em 2020 e 2021. Resultados: as atividades desenvolvidas pelos estudantes mostraram os desafios que envolvem a profissão no contexto de uma pandemia, alterações no processo de trabalho e a adequação a novos protocolos, que contribuíram na formação profissional e possibilitaram aos estudantes a oportunidade de vivenciar experiências no contexto da pandemia. Conclusão: o estágio curricular supervisionado favoreceu o crescimento pessoal, desenvolvimento de habilidades, competências, autonomia e liderança para lidar com diversas situações.
\end{abstract}

Palavras-chave: Educação em enfermagem; Infecções por coronavírus; Atenção primária à saúde.

\footnotetext{
ABSTRACT

Objective: to report the experiences of nursing students during the supervised curricular internship in primary care, in the context of the Coronavirus pandemic. Method: experience report developed by undergraduate nursing students during the supervised curricular internship in a primary care service, in the State of Rio Grande do Norte. The internship was developed in a Family Health

1 Estudante do Curso de Enfermagem da Universidade Federal do Rio Grande do Norte. E-mail: viniciusalsouza@hotmail.com;

2 Estudante do Curso de Enfermagem da Universidade Federal do Rio Grande do Norte. E-mail: barraisa20@gmail.com;

3 Estudante do Curso de Enfermagem da Universidade Federal do Rio Grande do Norte. E-mail: anaklasilva@gmail.com;

4 Estudante do Curso de Enfermagem da Universidade Federal do Rio Grande do Norte. E-mail: paulow123@outlook.com;

${ }^{5}$ Enfermeira da Estratégia de Saúde da Família, Natal, RN. E-mail: magnoliagonzaga@hotmail.com;

6 Professora do Departamento de Enfermagem da Universidade Federal do Rio Grande do Norte. E-mail: paulafernandabbs@gmail.com.
} 


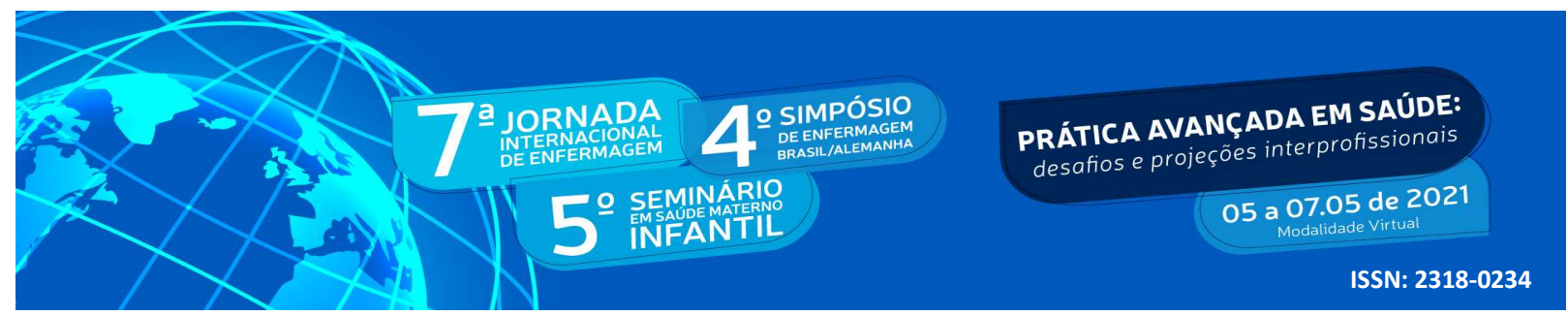

Strategy in 2020 and 2021. Results: the activities developed by the students showed the challenges that involve the profession in the context of a pandemic, changes in the work process and the adaptation to new protocols, which contributed to the professional training and provided students with the opportunity to live experiences in the context of the pandemic. Conclusion: the supervised curricular internship favored personal growth, development of skills, competences, autonomy and leadership to deal with different situations.

Key Words: Education, Nursing; Coronavirus Infections; Primary Health Care.

\section{INTRODUÇÃO}

Em dezembro de 2019, uma nova doença semelhante à pneumonia foi notificada pela China à Organização Mundial de Saúde (OMS). Essa afecção viral, transmitida pelo novo coronavírus, foi denominada COVID-19. Na América Latina, a cidade de São Paulo registrou o primeiro caso, no Brasil, em fevereiro de 2020. Em 11 de março de 2020, a OMS a reconheceu como uma pandemia (CAVALCANTE et al, 2020).

Esta nova infecção viral logo demonstrou seu poder de contágio e de agravamento dos quadros levando a síndrome respiratória grave com alta mortalidade. A ausência de tratamentos efetivos, o desconhecimento sobre o comportamento desse vírus e suas repercussões no organismo, além das dificuldades no manejo dos casos, fizeram com que ações de caráter mais restritivos tivessem necessidade de se impor. Era preciso diminuir o contato pessoa a pessoa, uma vez que esta era a principal via de contaminação.

Com a chegada da COVID-19 no Brasil, várias medidas para tentar o controle e prevenção da doença foram adotadas pelos órgãos de saúde do país em diferentes esferas governamentais (governo federal, governos estaduais e municipais). Essas práticas adotadas se diferenciariam de uma região para outra em todo território Brasileiro, contudo a conduta mais disseminada pelas autoridades sanitárias foi a do distanciamento social (PIRES, 2020).

Uma nova forma de viabilizar a formação estava ali sendo gestada. Não havia tempo oportuno para programar um ensino à distância, a pressão da população para a continuidade das atividades de ensino, a quarentena obrigatória e a própria pandemia fizeram nascer um novo processo de trabalho para os docentes, conhecido hoje por ensino remoto. Essa modalidade, conta com o uso de tecnologias para possibilitar o encontro virtual, a realização de aulas e 


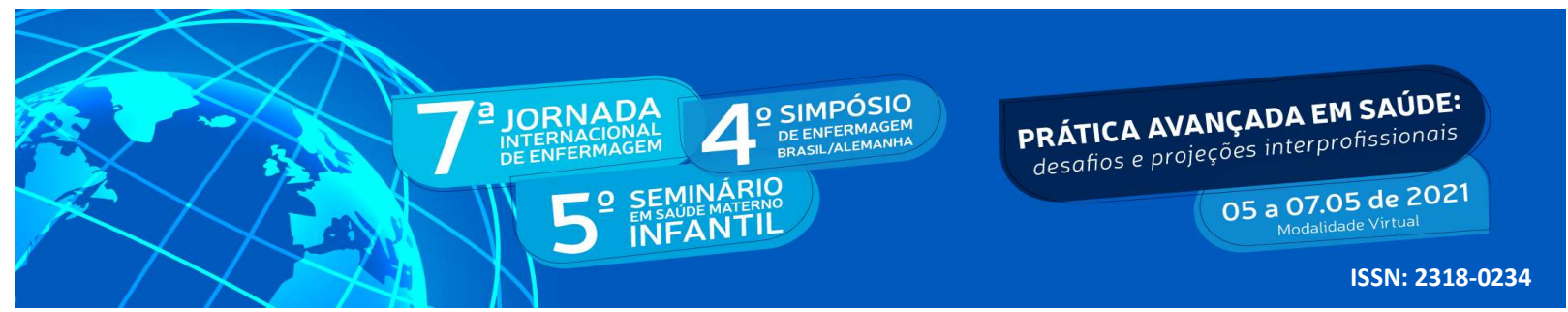

acompanhamento do processo de aprendizado dos estudantes. Foram mudanças impostas e necessárias a todos os níveis da educação no Brasil.

E em tempos de pandemia, a atuação docente e as concepções de ensino, aprendizagem e presencialidade foram reformuladas no âmbito das instâncias educacionais. Em decorrência desse período caótico, todos os cursos da Universidade Federal do Rio Grande do Norte (UFRN) precisaram repensar e adaptar o desenvolvimento das atividades para o formato remoto.

O curso de graduação em Enfermagem da UFRN também passou por esse processo. O curso visa a formação do bacharel em Enfermagem capaz de compreender e intervir no processo de produção dos serviços de saúde e atender às necessidades sociais relativas à sua área de atuação. O último ano do curso é para a realização do estágio supervisionado nos serviços públicos de saúde.

O Conselho Nacional de Educação, através das diretrizes curriculares para a formação do profissional enfermeiro prevê, na formação do mesmo, a oferta de componentes curriculares de estágios supervisionados nos dois últimos semestres do curso, sendo um deles na rede básica de serviços de saúde e comunidade, o qual deve contar com a supervisão direta pelos enfermeiros da própria instituição onde o estágio será realizado (NEGREIROS; LIMA, 2018).

O estágio supervisionado favorece a formação do aluno no vínculo educativo e profissionalizante o qual, proporciona aos estudantes o domínio de instrumentos teóricos e práticos, inserindo o aluno no cotidiano profissional e com isso, ampliando o entendimento sobre o meio que está inserido, as responsabilidades do trabalho, oportunidades para executar funções, lidar com as contingências diárias visando à promoção da saúde e com isso, tem a oportunidade, ainda durante a graduação, de avaliar os conhecimentos adquiridos, favorecer e desenvolver as habilidades obtidas.

Com a paralisação das atividades presenciais, o estágio supervisionado também foi interrompido em março de 2020 em todas as Universidades brasileiras, gerando angústias e preocupações nos estudantes e docentes dos cursos da área de saúde. No entanto, sendo esta experiência tão necessária e fundamental para a conclusão do curso de graduação, e vendo a necessidade de viabilizar o término destes estudantes para sua alocação no mercado de trabalho, 


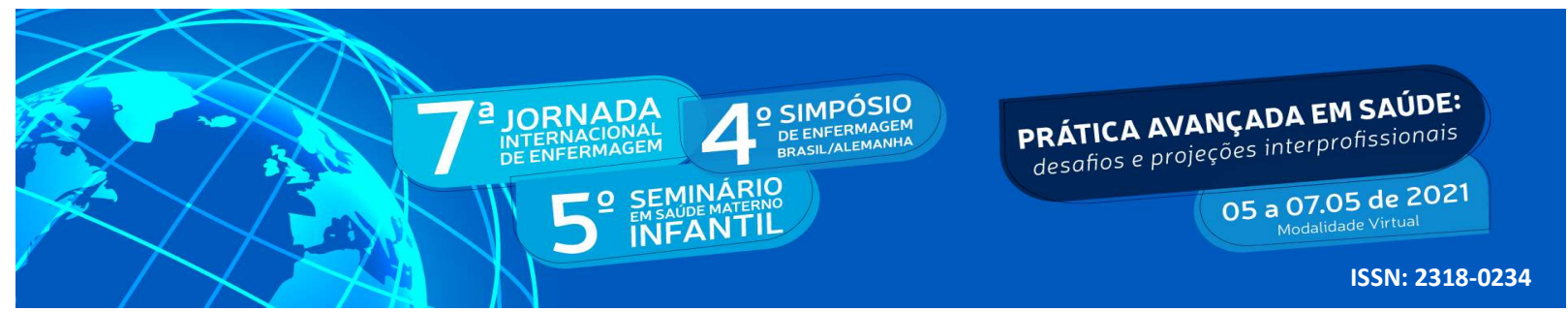

que já anunciava a necessidade de mais profissionais num espaço de tempo curto, estratégias para garantir a continuidade destas ações foram implementadas pelo governo federal através do programa "O Brasil Conta Comigo" que estimulou a partir do dia 23 de março de 2020 a continuidade dos estágios.

Criado como uma ação estratégica, o programa federal "O Brasil Conta Comigo", voltado aos alunos dos cursos da área de saúde, objetiva otimizar a disponibilização de serviços de saúde no âmbito do Sistema Único de Saúde (SUS) para o enfrentamento à pandemia do coronavírus COVID-19, de forma integrada com as atividades de graduação na área da saúde (BRASIL, 2020).

No entanto, nem todos os estudantes conseguiram retornar às suas atividades de estágio supervisionado. Naquele momento entre o desejo de continuar suas atividades e vivenciar um período ímpar da história da saúde pública no mundo estava também o medo, a angústia de não se sentir suficientemente preparado ou ainda o medo de adoecer, de morrer ou mesmo de ser responsável pelo adoecimento dos seus familiares.

O presente trabalho busca refletir sobre esse momento de estágio supervisionado durante a pandemia e fundamenta-se nas experiências desenvolvidas na prática do estágio supervisionado 1 na atenção básica, de caráter obrigatório, no início de março de 2020, sendo interrompido devido a pandemia do covid-19, o qual foi retornado dia 23 de setembro de 2020 e concluído dia 16 de dezembro de 2020, em uma unidade saúde da família, localizada no bairro de Felipe camarão, distrito oeste da cidade de Natal/RN.

\section{OBJETIVO}

Relatar as experiências de estudantes de enfermagem durante o estágio curricular supervisionado na atenção primária em uma unidade de saúde da família no cenário da pandemia de Coronavírus.

\section{METODOLOGIA}




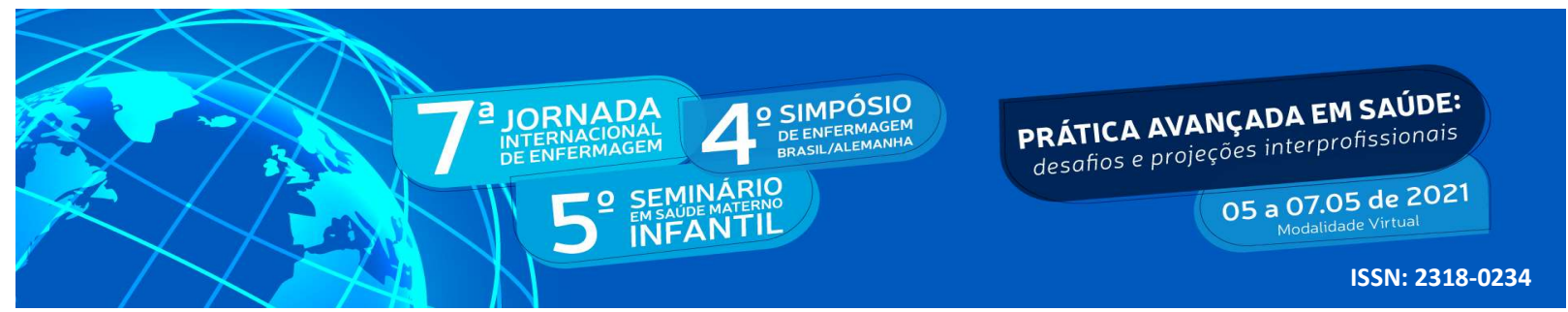

Trata-se de um relato de experiência, descritivo, sobre as vivências dos estudantes do curso de graduação em Enfermagem da Universidade Federal do Rio Grande do Norte, durante o Estágio Curricular Supervisionado I - O processo de trabalho do enfermeiro na Atenção Básica de Saúde, realizado em uma unidade de saúde da família no contexto da pandemia do COVID-19, em 2020 e 2021.

A Unidade de Saúde Família (USF) trata-se de um serviço público e gratuito, vinculado à Secretaria Municipal de Saúde de Natal e ao Sistema Único de Saúde, sendo composta por quatro Equipes de Saúde da Família, composta por Agentes Comunitários de Saúde (ACS), Enfermeiras e Médicos. Entre os serviços oferecidos pela instituição de saúde encontram-se o acolhimento; consultas de pré-natal da mulher e planejamento reprodutivo; consultas de crescimento e desenvolvimento infantil; consultas para acompanhamento de comorbidades; visitas domiciliares; vacinação; curativos; administração de medicamentos, entre outros.

A Unidade de Saúde da Família em que foi desenvolvido o relato está situada na região oeste do município de Natal no Rio Grande do Norte. Esse serviço tem uma população adscrita de aproximadamente 12.433 usuários cadastrados. Compreende a Rede de Atenção à Saúde do município e atende a população por demanda espontânea e por agendamentos.

A Unidade de Saúde da Família, onde ocorreu o estágio, tornou-se referência para atendimentos de sintomáticos respiratórios. Assim, ela auxilia na identificação de casos suspeitos e encaminha os usuários para os demais pontos da Rede de Atenção à Saúde, quando necessário. Para a realização destas ações estratégicas também foi estendido o seu horário de funcionamento, e em formato de rodízio entre as equipes, a unidade oferece um atendimento das 07:00 horas às 19:00 horas.

\section{DESENVOLVIMENTO}

Com o advento da pandemia da Covid-19 (SARS-CoV-2), declarada pela Organização Mundial de Saúde (OMS) em março de 2020, e a ausência de recursos financeiros emergenciais que suprissem as necessidades de segurança dos estagiários diante desse cenário, os estágios 


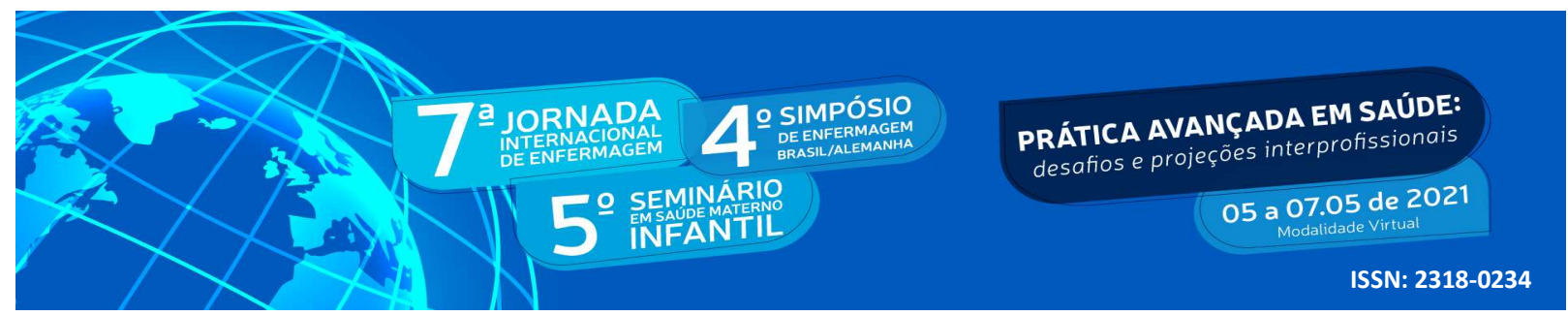

curriculares obrigatórios foram suspensos, sem previsão de retorno. Para nós enfermeirandos foi impactante interromper as atividades finais do curso, sem previsão de retorno.

Após várias discussões entre estudantes, professores, coordenadores e representantes de órgãos de saúde municipal e estadual, ficou decidido o retorno facultativo dos estagiários aos campos de práticas após seis meses desde o início da pandemia. Apesar do desejo em retomar as atividades do curso, principalmente pela ansiedade em graduar-se enfermeiros, tomar essa decisão de retorno no contexto atual foi uma das mais difíceis do curso. $\mathrm{O}$ fato de ser uma doença pouco conhecida e de evolução grave fez com que alguns de nós recusasse, a princípio, a proposta de retorno. Por outro lado, outros estagiários resolveram retomar as atividades imediatamente mediante oferta de equipamentos de proteção e treinamento.

Para tanto, foi necessário o desenvolvimento de competências e habilidades direcionadas ao contexto atual. Antes do retorno às atividades realizamos cursos teóricopráticos, de caráter obrigatório, em plataformas digitais. Esses cursos abordaram as características biológicas do agente etiológico da COVID-19, os aspectos clínicos da doença, o manejo de adultos e idosos na Atenção Primária à Saúde (APS), as medidas de prevenção do contágio e a importância da paramentação e da desparamentação correta, assim como a descrição audiovisual dessas etapas de segurança, que serviram de base para o desenvolvimento das habilidades de proteção individual.

Com a aquisição do aporte teórico necessário para compreender o contexto atual, iniciamos nossas atividades práticas em uma Unidade de Saúde da Família na Zona Oeste de Natal - RN. No primeiro momento, várias inseguranças surgiram ao adentrar em um serviço de saúde após os seis meses em isolamento físico, por ainda tratar-se de um cenário pandêmico. Apesar da utilização correta dos Equipamentos de Proteção Individual (EPI), o medo em contaminar-se e, de certa forma, oferecer mais riscos de contaminação aos familiares foi um sentimento vivido constantemente por todos os estagiários durante as práticas.

A monitorização pessoal acerca dos sinais e sintomas da doença foi realizada diariamente com a finalidade de identificar uma possível infecção em tempo hábil e diminuir a possibilidade de transmissão do vírus através do isolamento individual. Outras estratégias utilizadas em nossa rotina foram o isolamento preventivo, no qual ficamos em cômodos 


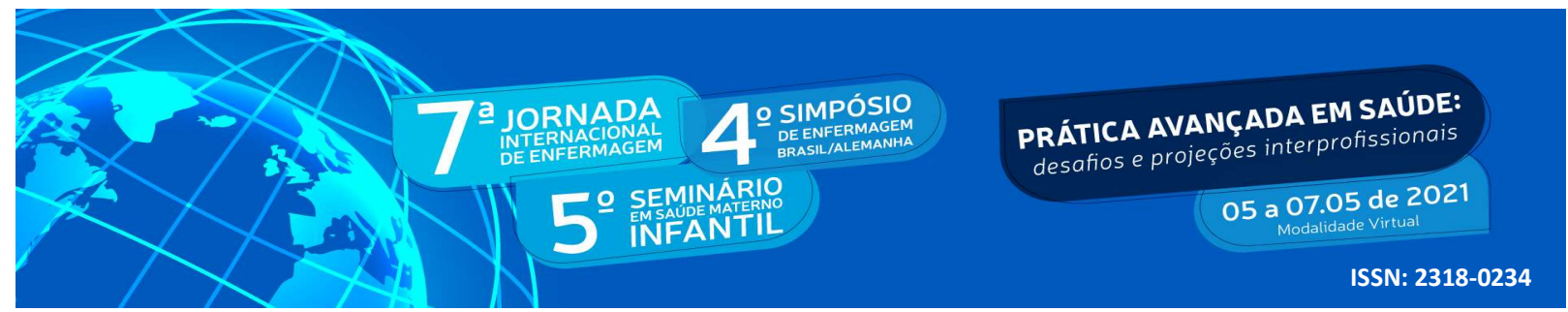

separados de todos os familiares, havendo o menor contato possível no dia a dia; a retirada dos calçados antes de adentrar a casa; a utilização da máscara ao adentrar ambientes comuns em nossas residências e demais medidas, para que se evitasse uma possível contaminação.

Em relação às atividades, houve uma redução geral no número de agendamentos para consultas, assim como a suspensão e/ou readequação de alguns serviços geralmente oferecidos pela unidade. Em relação à saúde materno-infantil, as consultas de puericultura subsequentes foram reduzidas para minimizar a exposição do binômio, priorizando a primeira consulta ao recém-nascido e a consulta à puérpera.

Já no que se refere à saúde da mulher, as consultas de pré-natal foram mantidas conforme recomendações do Ministério da Saúde, porém houve significativa redução nos agendamentos para coleta de citologia oncótica.

Foram suspensas as atividades com grupos de Crescimento e Desenvolvimento Coletivo, Grupo de Autocuidado e demais atividades educativas em saúde, as quais poderiam haver aglomeração de pessoas. Devido a suspensão das aulas municipais, estaduais e federal, não houve a possibilidade de realizar atividades da Saúde na Escola. As visitas domiciliares também foram reduzidas, havendo prioridade à idosos e acamados, pacientes com doenças crônicas descompensadas, além de ocasiões especiais as quais necessitavam acompanhamento direto.

Apesar desses desafios, algumas atividades de promoção à saúde foram realizadas na sala de espera da unidade para aqueles usuários que aguardavam atendimento. Outras ações de promoção à saúde foram realizadas dentro do próprio consultório, individualmente.

Uma das preocupações dos docentes e discentes durante o estágio supervisionado nesse cenário de pandemia era a possibilidade de não desenvolver a contento as habilidades e competências esperadas, uma vez que mudanças significativas no processo de trabalho das equipes poderiam interferir diretamente no aprendizado de condições essenciais para a formação do enfermeiro na Atenção Primária à Saúde. Entretanto, apesar das modificações no processo de trabalho, conseguimos executar a maioria das atividades a serem desenvolvidas pelos estagiários. 


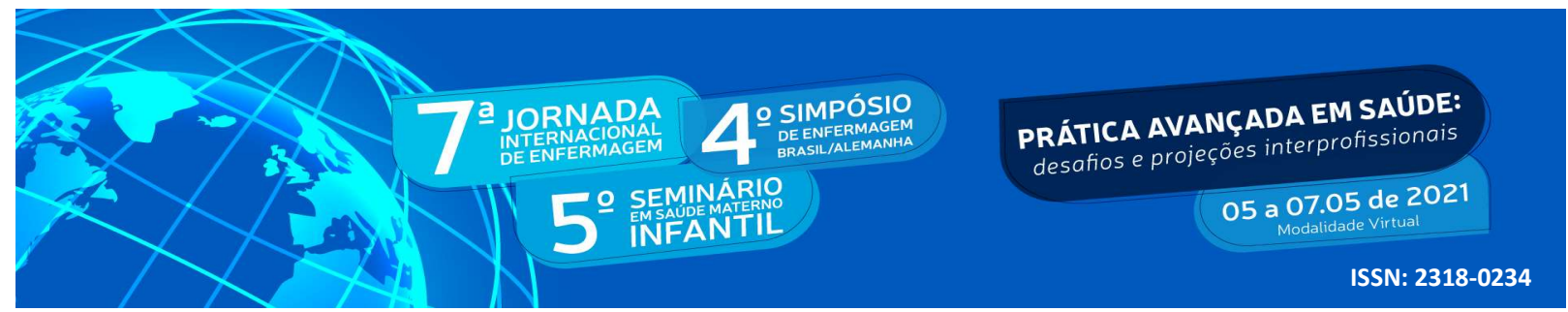

Nesse sentido, é possível perceber que tivemos perdas e ganhos nesse processo. A ausência de algumas atividades nos impuseram limites para o desenvolvimento de algumas competências e habilidades. No entanto, isso não gerou maiores limitações ou fragilidades à formação uma vez que ao longo do curso nos foi proporcionado uma inserção forte nos cenários de prática com o desenvolvimento de habilidades e competências para o trabalho da atenção primária à saúde desde o primeiro semestre do curso.

Sendo assim, foi possível identificar algumas lacunas durante o estágio supervisionado, entretanto sem que houvesse prejuízos graves à nossa formação. Por outro lado, os ganhos também foram expressivos, pois nessa ocasião houve um amadurecimento pessoal e profissional; foi possível realizar o desenvolvimento da autonomia, a capacidade de resposta em cenários difíceis, o desafio de se constituir um profissional de saúde em meio a um momento de incertezas, medos e novos aprendizados. $\mathrm{O}$ fortalecimento da resiliência, de se antepor às adversidades e superar os desafios também foram ganhos decorrentes desse processo.

O estágio supervisionado além de nos permitir conhecer a realidade da Atenção Primária e aplicar nossos conhecimentos ao processo de trabalho do enfermeiro, nos proporcionou trocar conhecimentos com as enfermeiras, vivenciar o trabalho multiprofissional, desenvolver competências e estratégias no cenário de pandemia, que contribuíram para a nossa formação profissional.

\section{CONCLUSÃO}

O Estágio Supervisionado na Atenção Básica no contexto da pandemia colaborou para a formação do perfil profissional dos estudantes, oportunizou novas experiências e aprendizado, aprimoramento das habilidades ao cuidado do indivíduo em todas as suas fases de vida. As mudanças necessárias para manter os atendimentos e ao mesmo tempo proteger tanto os profissionais como a população usuária da unidade requisitou dos acadêmicos uma readaptação imediata a realidade da instituição e a forma de atuação já praticada há algum tempo, isso contribuiu para ao crescimento pessoal e profissional de cada aluno inserido naquele contexto.

Um contexto de pandemia, sem dúvida, é um contexto adverso ao que está previsto nos 


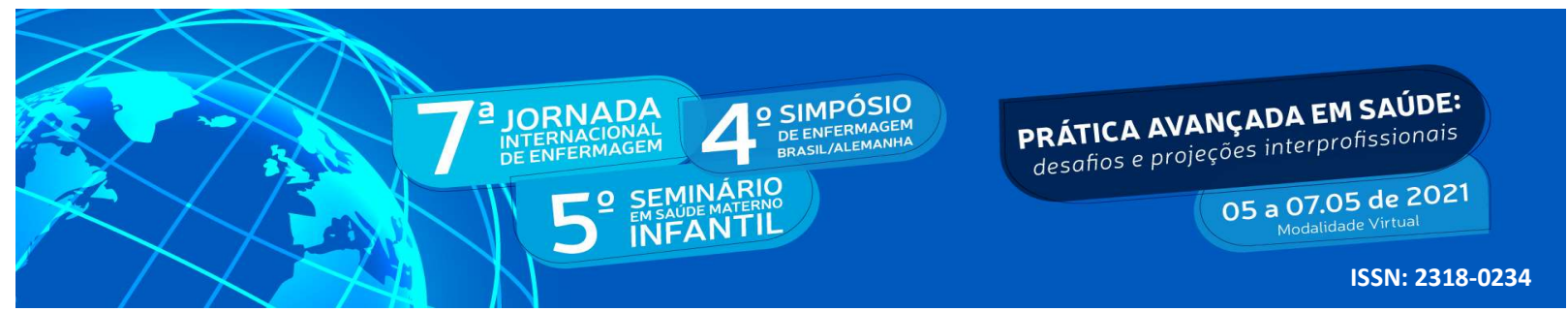

nossos projetos pedagógicos de formação profissional, pois envolve uma reorganização dos processos de trabalho, um foco em ações estratégias de prevenção e promoção a determinado evento em detrimento de outros. Sem dúvida, a evidência maior está relacionada ao agente infeccioso e a sua repercussão na saúde e na vida das pessoas.

No entanto, para além do adoecimento da Covid-19, os usuários do serviço também se mantêm susceptíveis aos demais processos de adoecimento para o qual a atenção primária deve seguir vigilante. Em tempos de pandemia, a saúde não pode ser reduzida a contenção de um vírus e é a atenção primária que mantém a constante vigilância dos eventos, e ela deve adaptarse à nova realidade para minimizar a persistência da pandemia ao mesmo tempo que desenvolve suas atividades para com a saúde da população.

Assim, atuar na atenção primária, em tempos de pandemia, reforça ainda mais em nós, estudantes, o compromisso com a saúde pública, com a vida e com a vigilância em saúde que precisam estar na pauta diária da atenção primária.

\section{REFERÊNCIAS}

BRASIL. Ministério da Saúde. Gabinete do Ministro. Portaria n ${ }^{0} 492$, de 23 de março de 2020. Institui a Ação Estratégica "O Brasil Conta Comigo", voltada aos alunos dos cursos da área de saúde, para o enfrentamento à pandemia do coronavírus (COVID-19). Diário Oficial da União: seção 1, Brasília, DF, p. 4, 2020. Disponível em: <

https://bvsms.saude.gov.br/bvs/saudelegis/gm/2020/prt0492_23_03_2020.html>.

CAVALCANTE, J. R. et al. COVID-19 en Brasil: evolución de la epidemia hasta la semana epidemiológica 20 de 2020. Rev. Epidemiol. Serv. Saúde v. 29 c.4. Brasília, 2020.

Disponível em: < https://www.scielosp.org/article/ress/2020.v29n4/e2020376/\#>.

PIRES, R. R. C. Os efeitos sobre grupos sociais e territórios vulnerabilizados das medidas de enfrentamento à crise sanitária da covid-19: propostas para o aperfeiçoamento da ação pública: Nota Técnica. Brasília: IPEA; 2020. Disponível em:

$<\underline{\text { http://repositorio.ipea.gov.br/handle/11058/9839>. }}$.

NEGREIROS, R. V; LIMA, V. C. Importância do estágio supervisionado para o acadêmico de enfermagem no hospital: compartilhando experiências vivenciadas com a equipe de trabalho. Revista da Universidade Vale do Rio Verde. v. 16, n. 2, 2018. Disponível em $<\underline{\text { http://periodicos.unincor.br/index.php/revistaunincor/article/view/4359/pdf_819>. }}$. 